\title{
Prospek Pengembangan Budidaya Jambu Madu Deli Hijau Di Kelurahan Sumber Karya Kecamatan Binjai Timur Kota Binjai (Studi Kasus Pada Usaha Rizki Jambu Madu) \\ (Aquaculture Development Prospects Cashew Honey Deli Green At Work Source Sub District of Eastern Binjai Binjai (A Case Study of Business Rizki Cashew Honey)
}

\author{
Tika Nurjannah Rangkuti ${ }^{1}$, Irwan A. Kadir ${ }^{1}$, Indra ${ }^{1}$ \\ ${ }^{1}$ Program Studi Agribisnis, Fakultas Pertanian, Universitas Syiah Kuala
}

\begin{abstract}
Abstrak- Tanaman jambu deli hijau termasuk tanaman tropis yang sangat mudah beradaptasi diberbagai lingkungan.Curah hujan yang ideal untuk pertumbuhan dan perkembangan tanaman jambu madu deli hijau adalah $50 \mathrm{~mm} / \mathrm{bulan}$ dan 214 $\mathrm{mm} / \mathrm{tahun}$.Tujuan penelitian ini yaitu untuk mengetahui prospek pengembangan budidaya jambu madu deli hijau yang ditinjau dari aspek teknis, aspek finansial dan aspek pasar. Metode penelitian yang digunakan adalah metode studi kasus (case study). Metode analisis yang digunakan untuk menganalisis aspek finansial adalah analisis kriteria investasi, untuk menganalisis aspek teknis dan aspek pasar menggunakan metode analisis deskriptif.Hasil penelitian menunjukkan bahwa aspek finansial usahatani jambu madu deli hijau layak untuk diusahakan karena $\mathrm{NPV}>0$, Net B/C > 1, IRR > dari suku bunga bank, dan BEP terjadi pada tahun ke-3.Aspek teknis menunjukkan bahwa budidaya jambu madu deli hijau layak untuk diusahakan dan pada aspek pasar menunjukkan bahwa permintaan jambu madu deli hijau setiap tahunnya mengalami peningkatan dengan harga mencapai Rp. 25.000 - Rp. 49.000/Kg.
\end{abstract}

Kata Kunci: Jambu Madu Deli Hijau, Budidaya, Prospek Pengembangan JambuMadu Deli Hijau.

Abstract- Deli honey green guava plants, including tropical plants are very adaptable in various environments. Rainfall is ideal for the growth and development deli honey green guava plants is $50 \mathrm{~nm} / \mathrm{month}$ and $214 \mathrm{~mm} /$ year. The purpose of this study is to determine the prospects for aquaculture development Deli honey green guava in terms of technical aspects, financial aspects and aspects of the market. The research method used was the case study method.the analytical methods used to analyze the financial aspect is the analysis of investment criteria, to analyze the technical aspects and market aspects of using descriptive analysis. The results showed that the financial aspects of farming deli honey green guava feasible to be developed because the NVP $>0$, Net B/C $>1$, IRR > of the bank rate and BEP occur in 3 year. Technical aspects show that the cultivation of deli honey green guava feasible to be developed and on the aspects of the market suggests that demand deli honey green guava every year has increased at a price of RP. $25.000-\mathrm{Rp} .49 .000 / \mathrm{Kg}$. 
Keywords: Deli honey green guava, Cultivation, Development Prospects Deli Honey Green Guava.

\section{PENDAHULUAN}

Jambu madu adalah salah satu buah-buahan yang menjadi wacana di Indonesia namun tidak gampang untuk mendapatkan buahnya.Bukan saja di Indonesia tapi negara luarpun lagi menyoroti buah jambu madu ini, baik Singapura, Malaysia, hingga Jepang.Saat ini di Kota Binjai Sumatera Utara, buah yang sangat populer dan paling banyak digemari oleh konsumen yaitu buah jambu madu deli hijau, karena jambu madu deli hijau ini berbeda dengan jambu air pada umumnya.

Jambu madu deli hijau mulai dibudidayakan di daerah Stabat sejak tahun 2006 dan mulai menyebar pembudidaya jambu madu deli hijau tersebut ke Kota Binjai sekitar tahun 2010. Jambu madu deli hijau pertama kali masuk ke Indonesia dibawa oleh seorang perempuan keturunan China yang tinggal di Deli Tua, Sumatera Utara, jambu madu deli hijau tersebut di bawanya dari Taiwan (Tribun News.com).

Sebagai negara yang banyak memiliki keanekaragaman jenis buah. Keanekaragaman ini tampak dari rasanya yang manis, asam, sepat maupun pahit. Keanekaragaman ini juga dapat dilihat dari bentuknya yang bulat maupun lonjong, ukurannya yang kecil maupun besar, dari tekstur kulit luarnya yang mulus, berlekuk, maupun berduri, bahkan dari warnanya yang hijau, kuning, jingga, maupun merah.Dari berbagai jenis buah di Indonesia, ada sebagian yang dapat dikatakan buah komersial.Buah yang komersial merupakan buah yang sangat digemari oleh konsumen. Buah yang demikian umumnya rasanya enak, penampilannya menarik, nilai jualnya menguntungkan( Nazaruddin, 1994 ).

Jambu madu deli hijau termasuk tanaman buah komersial yang sangat digemari oleh konsumen. Jambu madu deli hijau memiliki keunggulan dibandingkan dengan jambu air pada umumnya, seperti : Mudah dalam budidaya (Tabulampot), produksi buah yang tinggi, memiliki harga jual yang relatif mahal, masa berbuahnya lebih cepat yaitu 9 bulan sampai dengan 1,5 tahun setelah masa tanam, memiliki rasa yang sangat manis hingga 15 Brix, dan memiliki bobot buah yang cukup besar yaitu sekitar 1,5 - 2 Ons, serta perawatannya tidak terlalu sulit.

Berdasarkan hasil survei, alasan petani mengusahakan buah jambu madu karena tertarik dengan nilai ekonomis yang tinggi dan jika dilihat dari permintaan pasar yang semakin meningkat menunjukkan bahwa jambu madu deli hijau sangat banyak diminati oleh konsumen pada saat ini.Tujuan pelaksanaan penelitian ini adalah untuk mengetahui prospek pengembangan usahatani jambu madu deli hijau jika ditinjau dari aspek teknis, aspek pasar, dan aspek finansial. 


\section{Lokasi, Objek, dan Ruang Lingkup Penelitian}

Penelitian ini dilakukan di Kecamatan Binjai Timur Kota Binjai. Penentuan Lokasi penelitian ini dilakukan pada Usaha Rizki Jambu Madu di Kelurahan Sumber Karya Kecamatan Binjai Timur Kota Binjai dilakukan secara sengaja (purpose sampling) dengan pertimbangan bahwa daerah tersebut terdapat petani yang mengusahakan budidaya tanaman buah jambu madu deli hijau dan daerah ini termasuk daerah yang potensial untukpengembangan budidaya tanaman jambu madu deli hijau. Objek penelitiannya adalah petani jambu madu deli hijau.Ruang lingkup penelitian ini terbatas pada prospek pengembangan usaha tersebut yang ditinjau dari aspek teknis, aspek finansial, maupun apsek pasar.

\section{Metode Penelitian dan Pengumpulan Data}

Metode penelitian yang digunakan adalah metode studi kasus (Case Study), karena metode ini memusatkan perhatian dan mengungkapkan kebenaran yang menitikberatkan hanya pada satu objek (Nazir, 2005).Usahatani budidaya jambu madu deli hijau di Kelurahan Sumber Karya Kecamatan Binjai Timur Kota Binjai.

Pengumpulan data yang digunakan dalam penelitian ini terdiri dari data primer dan data sekunder.Data primer yaitu data yang diperoleh dari pengamatan langsung di lapangan dan wawancara terhadap pengelola usahatani budidaya jambu madu deli hijau.Data sekunder yaitu data yang diperoleh dari perpustakaan, instansi terkait, browsing internet atau literatur yang terkait dalam penelitian ini.

\section{Metode Analisis}

Berdasarkan data yang telah dikumpulkan di lapangan, dipindahkan dan ditabulasikan kemudian diolah dalam bentuk tabelaris sesuai dengan kebutuhan analisis.

\section{Analisis Aspek Teknis}

Pada aspek teknis, metode analisis yang digunakan adalah metode analisis deskriptif, dimana metode deskriptif adalah penelitian yang berusaha menggambarkan dan menginterprestasikan objek sesuai dengan yang terjadi di lapangan.

\section{Analisis kelayakan Finansial}

\section{Net Present Value (NPV)}

Net Present Value (NPV) adalah nilai sekarang dari selisih antara benefit (manfaat) dengan (biaya) pada Discount Rate tertentu. Dengan rumus sebagai berikut:

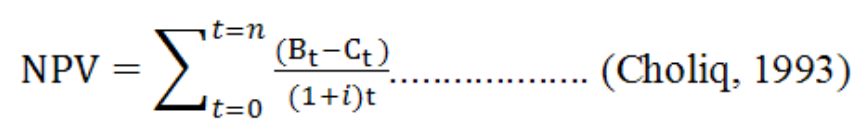

Dimana :

$\mathrm{Bt}=$ Benefit pada tahun ke $\mathrm{t}$

$\mathrm{Ct}=$ Cost pada tahun ke $\mathrm{t}$

$\mathrm{i}=$ Tingkat bunga yang berlaku (Discount Rate)

$\mathrm{n}=$ Umur ekonomis usaha

Jika NPV > 0, maka usahatani layak untuk diusahakan dan menguntungkan.

Jika NPV $=0$, maka usahatani tersebut tidak untung dan tidak rugi.

Jika NPV $<0$, maka usahatani tersebut tidak layak untuk diusahakan. 


\section{Net Benefit Cost Ratio (Net B/C)}

Net B/C adalah perbandingan antara julah Net Present Value positf (NPV positf) dengan Net Present Value negatif (NPV negatif). Dengan rumus sebagai berikut:

Dimana :

$$
\text { Net } \mathrm{B} / \mathrm{C}=\frac{\sum_{t=0}^{t-n} \frac{\left(\mathrm{B}_{\mathrm{t}-} \mathrm{C}_{\mathrm{t}}\right)}{(1+\mathrm{i})^{\mathrm{t}}}(\text { Positif })}{\sum_{t=0}^{t-n} \frac{\left(\mathrm{B}_{\mathrm{t}-\mathrm{C}_{\mathrm{t}}}\right)}{(1+\mathrm{i})^{\mathrm{t}}}(\text { Negatif })} \ldots .(\text { Choliq }, 1993)
$$

$$
\begin{aligned}
\mathrm{Bt} & =\text { Manfaat setiap tahun } \\
\mathrm{Ct} & =\text { Biaya tiap tahun } \\
\mathrm{t} & =\text { Tahun } 1,2,3 \ldots \ldots . \mathrm{n} \\
\mathrm{n} & =\text { Umur ekonomis tanaman } \\
\mathrm{i} & =\text { Tingkat bunga yang berlaku }
\end{aligned}
$$

Jika Net B/C > 1, maka usahatani tersebut layak untuk diusahakan.

Jika Net $\mathrm{B} / \mathrm{C}=1$, maka usahatani tersebut tidak untung dan tidak rugi.

Jika Net $\mathrm{B} / \mathrm{C}<1$, maka usahatani tersebut tidak layak untuk diusahakan.

\section{Internal Rate of Return (IRR)}

IRR merupakan nilai untuk mengetahui presentase keuntungan dari usaha tiap-tiap tahun.IRR juga merupakan alat ukur kemampuan proyek dalam mengembalikan bunga pinjaman. Dengan rumus sebagai berikut:

$$
\begin{aligned}
& I R R=i_{1}+\frac{\mathrm{NPV}(\text { positif })}{\operatorname{NPV}(\text { positif })}\left(\mathrm{i}_{2} \mathrm{i}_{1}\right) \ldots(\text { Cholia. } 1993) \\
& I R R=i_{1}+\frac{\left.\mathrm{N}_{2}-\mathrm{i}_{1}\right) \ldots(\text { Choliq }, 1993)}{\mathrm{NPV}(\text { positif })-\mathrm{NPV}(\text { negatif })}
\end{aligned}
$$

$\mathrm{i}_{1}=$ Tingkat bunga pada percobaan pertama dimana diperoleh NPV positif.

$\mathrm{i}_{2}=$ Tingkat bunga pada percobaan kedua dimana diperoleh NPV negatif.

$\mathrm{NPV}($ positif $)=$ Nilai NPV pada tingkat bunga $i_{1}$ (positif menuju nol).

NPV $($ negatif $)=$ Nilai NPV pada tingkat bunga $i_{1}($ negatif menuju nol).

Jika IRR > Discount rate, maka usahatani layak diusahakan.

Jika IRR = Discount rate, maka usahatani tersebut pada titik impas dan layak diusahakan.

Jika IRR < Discount rate, maka usahatani tersebut layak diusahakan.

\section{Break Event Point (BEP)}

Break Event Point (BEP) adalah titik balik modal dimana penerimaan sama dengan biaya. Dengan rumus sebagai berikut:

$$
B E P=\mathrm{T}_{\mathrm{p}-1}+\frac{\sum_{\mathrm{t}=00}^{\mathrm{t}=\mathrm{n}_{1}} \mathrm{TC}_{1}-\sum_{\mathrm{t}=0}^{\mathrm{t}=\mathrm{n}} \mathrm{Biep}-1}{\mathrm{Bp}} \ldots(\text { Ibrahim,1998) }
$$


Dimana :

$\mathrm{T}_{\mathrm{p}-\mathrm{t}} \quad=$ Tahun sebelum terdapat BEP

$\mathrm{TC}_{\mathrm{i}} \quad=$ Jumlah total cost yang telah di discount

$\mathrm{B}$ icp- ${ }_{1}=$ Jumlah benefit yang telah di discount sebelum BEP

$\mathrm{B}_{\mathrm{p}} \quad=$ Jumlah benefit pada tahun terjadinya BEP

$\mathrm{n} \quad=$ Umur ekonomis usaha

BEP menunjukkan jika suatu usaha atau proyek dalam keadaan tidak mengalami keuntungan juga tidak mengalami kerugian atau dengan kata lain apabila penghasilan (total revenue) sama dengan biaya yang dikeluarkan (total cost).

\section{Analisis Sensitivitas}

Analisis sensitivitas atau analisis kepekaan bertujuan untuk melihat kemungkinan-kemungkinan yang terjadi dari hasil analisis usaha. Jika ada suatu kesalahan perhitungan biaya dan manfaat serta perubahan-perubahan yang tidak diduga sebelumnya. Dalam menggunakan analisis sensitivitas digunakan beberapa asumsi sebagai berikut:

1). Asumsi I : Biaya operasional naik $10 \%$ sedangkan benefit tetap

2). Asumsi II : Biaya operasional tetap sedangkan benefit turun $10 \%$

\section{Analisis Trend Produksi}

Untuk melihat perkiraan produksi jambu madu deli hijau selama 5 tahun yang akan datang, dalam penelitian ini digunakan metode analisis Logaritma Natural (Ln) yang dihitung dengan bantuan program Excel.

\section{Analisis Aspek Pasar}

Pada aspek pasar, menggunakan metode analisis deskriptif untuk mengetahui permintaan jambu madu deli hijau, dimana metode deskriptif adalah penelitian yang berusaha menggambarkan dan menginterprestasikan objek sesuai dengan yang terjadi di lapangan. Sedangkan untuk melihat harga buah naga menggunakan metode analisis pertumbuhan.

\section{Karakteristik Petani}

\section{HASIL DAN PEMBAHASAN}

Karakteristik petani adalah keadaan dimana gambaran dari petani yang berkaitan dan dapat mempengaruhi aktifitas yang dilakukan. Karakteristik yang dimaksud dalam penelitian ini meliputi umur, pendidikan, pengalaman dan luas lahan yang dikelola. Karakteristik akan mempengaruhi kemajuan kerja petani dalam meningkatkan produksi untuk mencapai tujuan yang diinginkan dalam berusahatani.Hasil penelitian memperlihatkan keadaan karakteristik pemilik usahatani budidaya jambu madu deli hijau di daerah penelitian dapat dilihat pada Tabel 1.

Dari Tabel 1 dapat dilihat karakteristik petani pemilik usahatani jambu madu deli hijau petani tersebut sudah selama 5 tahun berpengalaman dalam membudidayakan jambu madu deli hijau dengan luas lahan yang dimiliki 0,5 Ha, mengikuti jenjang pendidikan selama 12 tahun dan saat ini sudah berusia 58 
tahun. Petani jambu madu deli hijau yang berada di Kelurahan Sumber Karya Kecamatan Binjai Timur Kota Binjai ini adalah bernama bapak dudo.

Tabel 1. Karakteristik Pemilik Usahatani Jambu Madu Deli Hijau di Daerah Penelitian

\begin{tabular}{|c|l|c|}
\hline No & \multicolumn{1}{|c|}{ Karakteristik } & Satuan \\
\hline 1 & Umur & 58 tahun \\
\hline 2 & Pendidikan & 12 tahun \\
\hline 3 & Pengalaman & 5 tahun \\
\hline 4 & Luas lahan & $0,5 \mathrm{Ha}$ \\
\hline
\end{tabular}

Sumber : Data Primer, 2015

\section{Aspek Teknis}

Aspek teknis adalah salah satu aspek yang penting untuk diperhatikan dalam usahatani budidaya jambu madu deli hijau karena apabila ada kesalahan dalam menentukan aspek ini maka usaha akan mengalami kegagalan. Dalam budidaya jambu madu deli hijau ini aspek teknis memiliki prospek yang baik untuk kedepannya hal ini dapat dilihat dari lahan usahatani yang dimiliki oleh petani, adanya tenaga kerja yang tetap untuk merawat tanaman jambu madu tersebut sehingga tanaman jambu madu deli hijau tersebut dapat berproduksi dengan baik karena adanya perawatan, jenis bibit jambu yang digunakan adalah bibit unggul serta pemupukan yang diberikan secara teratur sehingga hal ini dapat disimpulkan bahwa budidaya jambu madu deli hijau memiliki prospek yang baik jika dilihat dari aspek teknis.

\section{Input Produksi}

Penggunaan input produksi pada usahatani jambu madu deli hijau di Kelurahan Sumber Karya Kecamatan Binjai Timur Kota Binjai yaitu terdiri dari :

\section{Lahan Usahatani}

Lahan usahatani budidaya jambu madu deli hijau di daerah penelitian sebesar 0,5 Ha. Luas lahan akan sangat mempengaruhi jumlah produksi jambu madu deli hijau yang akan dihasilkan, semakin luas lahan usahatani jambu madu deli hijau maka akan semakin banyak tanaman jambu madu deli hijau yang dapat dibudidayakan.

\section{Tenaga Kerja}

Tenaga kerja yang digunakan dalam usahatani budidaya jambu madu deli hijau di daerah penelitian yaitu sebanyak 12 orang dimana dari 12 orang tenaga kerja tersebut terdiri dari 10 orang tenaga kerja tidak tetap dan 2 orang tenaga kerja tetap, dan tenaga kerja yang dipekerjakan berasal dari Kelurahan Sumber Karya Kecamatan Binjai Timur Kota Binjai. 


\section{Bibit}

Jenis bibit yang digunakan oleh petani jambu madu deli hijau di daerah penelitian adalah yang di dapatkan langsung dari salah satu sentra penangkaran bibit yang berada di Kecamatan Binjai Barat Kota Binjai.

\section{Pupuk}

Pemberian pupuk kandang pada tanaman jambu madu deli hijau dilakukan setiap dua minngu sekali dan pemberian pupuk cair NPK yaitu dengan dosis 10 gr/pokok. pada saat masa pertumbuhan dan ketika masa tanaman jambu madu deli hijau mulai berbuah pemberian pupuk NPK dengan dosis 20 gr/pokok, pemupukan dilakukan sekali dalam seminggu.

\section{Teknik Budidaya Jambu Madu Deli Hijau}

\section{Pengadaan Lahan}

Pengadaan lahan untuk membudidayakan jambu madu deli hijau tidak terlalu sulit, hanya saja perlu diperhatikan pembersihan lahan dari akar-akar tanaman pengganggu serta gulma-gulma yang ada agar lahan tersebut benar-benar steril.

\section{Tempat/Wadah}

Dalam penanaman jambu madu deli hijau dengan sistem tabulampot, maka tempat/wadah yang dijadikan sebagai tempat penanaman harus sangat diperhatikan, karena hal ini sangat mempengaruhi keberhasilan dari budidaya jambu dengan sistem tabulampot. Di daerah penelitian tempat/wadah yang digunakan yaitu pot yang terbuat dari drum bekas berdiameter $60 \mathrm{~cm}$.

\section{Media Tanam}

Media tanam termasuk bagian yang menentukan berhasil atau tidaknya budidaya jambu madu deli hijau. Tanah / kompos yang steril dari berbagai penyakit yang dapat mengganggu pertumbuhan tanaman baik cendawan maupun nematoda yang menyerang pada sistem perakaran tanaman.

\section{Pengadaan Bibit}

Bibit yang ditanam pertama kali pada daerah penelitian yaitu bibit yang berasal dari CV. Mulia Tani salah satu sentra penangkaran bibit yang berada di Kecamatan Binjai Barat Kota Binjai.

\section{Jarak Tanam}

Di daerah penelitian jarak tanam yang digunakan yaitu 2 × 3 m karena jarak ini sangat sesuai dengan percabangan dari jambu madu deli hijau, yang mempunyai karakter seperti kerucut sehingga tidak perlu jarak yang lebar.

\section{Perawatan dan Pemeliharaan Jambu Madu Deli Hijau}

Perawatan jambu madu deli hijau tidaklah sulit, bibit jambu yang telah ditanam perlu mendapatkan perawatan agar tumbuh dengan baik dan menghasilkan panen yang optimal. Pada umur $1-6$ bulan pertama masa pertumbuhan, maka unsur N ( Nitrogen ) harus lebih dominan agar percabangan dan batang lebih banyak dan kokoh. Jambu madu deli hijau dapat berbuah $9-12$ bulan setelah penanaman. 


\section{Aspek Finansial}

\section{Biaya Produksi}

Biaya produksi adalah biaya yang dikeluarkan oleh petani jambu madu deli hijau untuk menghasilkan sejumlah output.Biaya produksi yang dimaksud dalam penelitian ini adalah biaya investasi dan biaya operasional.

\section{Biaya Investasi}

Biaya investasi merupakan seluruh biaya yang dikeluarkan dari mulai usaha tersebut dilaksanakan sampai usaha tersebut mendapat penerimaan (benefit), atau dengan kata lain biaya investasi merupakan biaya yang dikeluarkan untuk membeli barang-barang modal selama usaha tersebut belum menghasilkan.

\section{a. Biaya Pra Investasi}

Biaya pra investasi merupakan biaya yang dikeluarkan sebelum proses pelaksanaan investasi atau modal awal untuk memulai usahatani. Perincian biaya pra investasi dalam usahatani budidaya jambu madu deli hijau ini adalah biaya untuk pembelian lahan.Perkiraan biaya pra investasi dapat dilihat pada Tabel 2.

Tabel 2. Rincian Biaya Pra Investasi Usahatani Budidaya Jambu Madu Deli Hijau di Kelurahan Sumber Karya kecamatan Binjai Timur Kota Binjai

\begin{tabular}{|c|l|c|c|c|}
\hline No & Uraian & Jumlah & Satuan & Jumlah Biaya (Rp) \\
\hline 1 & Pembelian Lahan & 0,5 & Ha & 35.000 .000 \\
\hline \multicolumn{3}{|c|}{ Jumlah } & 35.000 .000 \\
\hline
\end{tabular}

Sumber : Data Primer (diolah), 2015

Dari Tabel 4 diatas dapat dilihat rincian biaya pra investasi usahatani budidaya jambu madu deli hijau di Kelurahan Sumber Karya Kecamatan Binjai Timur Kota Binjai untuk pembelian lahan usahatani jambu madu deli hijau seluas 0,5Ha biaya yang dikeluarkan sebesar Rp. 35.000.000,

\section{Biaya Investasi Tanaman}

Biaya investasi tanaman merupakan seluruh biaya yang dikeluarkan dari proses pembukaan lahan sampai tanaman jambu madu deli hijau menghasilkan dari tahun ke-0 sampai tahun ke-10.Biaya pada tahun ke-0 Rp 175.010.000 dengan perincian biaya yang dikeluarkan untuk pengadaan lahan, sarana produksi, peralatan, dan biaya tenaga kerja.

\section{Biaya Operasional}

Biaya operasional merupakan seluruh biaya yang dikeluarkan selama proses produksi berlangsung, atau dengan kata lain biaya operasional adalah semua biaya yang dikeluarkan selama usahatani tersebut dapat menghasilkan buah jambu madu deli hijau yang siap di produksi.

Biaya operasional yang harus dikeluarkan dalam membudidayakan usahatani jambu madu deli hijau di dalam penelitian ini biaya operasional yang harus dikeluarkan yaitu untuk biaya pembelian pupuk kandang, pupuk cair (NPK), Obat-obatan, upah tenaga kerja dan pembelian plastik kemasan. 


\section{Arus Penerimaan}

\section{Produksi, Harga, dan Nilai Produksi}

Hasil produksi tanaman jambu madu deli hijau akan diperoleh pada saat tanaman berumur 12 bulan atau 16 bulan. Hasil produksi yang di dapat di daerah penelitian yaitu berkisar $4.800-6.000 \mathrm{Kg} /$ tahun dengan luas lahan 0,5 Ha. Hasil panen jambu madu deli hijau terus meningkat setiap tahunnya hal ini dapat dilihat bahwa selama 5 tahun usahatani jambu madu deli hijau yang telah dijalankan memperoleh hasil produksi yang cukup baik.

Nilai produksi adalah penerimaan kotor yang diterima dari rata-rata produksi per panen dikalikan dengan rata-rata harga jual yang berlaku pada saat penelitian. Pendapatan usahatani yang dimaksud dalam penelitian ini adalah total jumlah produksi dikalikan dengan harga jual yang berlaku dan dikurang dengan baiaya produksi yang dikeluarkan petani selama proses produksi berlangsung.

Pada tahun ke-1 sampai dengan tahun ke-5 adalah jumlah produksi yang diperoleh dari usahatani jambu madu deli hijau di daerah penelitian yaitu jumlah produksi yang didapat sebanyak $4.800 \mathrm{Kg} / \mathrm{Ha}$ sampai $6.200 \mathrm{Kg} / \mathrm{Ha}$. Kemudian pada tahun ke-6 sampai dengan tahun ke-10 adalah hasil jumlah produksi yang diprediksi dimana hasil jumlah produksinya mengalami penurunan yaitu sebanyak 9.276 $\mathrm{Kg} / \mathrm{Ha}$ sampai $9.513 \mathrm{Kg} / \mathrm{Ha}$. Harga jual yang berlaku pada saat penelitian yaitu $\mathrm{Rp}$ $25.000 / \mathrm{Kg}$, maka nilai produksi yang didapat oleh petani jambu madu deli hijau dalam satu tahun berkisar Rp 120.000.00 - Rp. 466.137 .000 per tahun.

\section{Analisis Kelayakan Finansial Dan Analisis Sensitivitas Usahatani Jambu Madu Deli Hijau \\ Analisis Kriteria Investasi}

Kelayakan usahatani jambu madu deli hijau dapat dilihat dengan menggunakan penilaian kriteria investasi yaitu NPV, Net B/C, IRR, dan BEP. Hasil perhitungan kriteria investasi secara komperhensif dapat dilihat pada lampiran 5, nilai dari kriteria penilaian investasi dapat dilihat pada Tabel 3.

Tabel 3. Nilai Kriteria Penilaian Investasi Pada Usahatani Budidaya Jambu Madu Deli Hijau

\begin{tabular}{|c|l|r|}
\hline No & \multicolumn{1}{|c|}{ Kriteria Investasi } & \multicolumn{1}{|c|}{ Nilai } \\
\hline 1 & Net Present Value (NPV) & Rp. 1.501.218.718 \\
\hline 2 & Net Benefit Cost Ratio (Net B/C) & $87,58 \%$ \\
\hline 3 & Internal Rate Of Rreturn (IRR) & 3 tahun, 5 bulan, 15 hari. \\
\hline 4 & Break Event Point (BEP) & \\
\hline
\end{tabular}

Sumber :Data Primer (diolah), 2015

\section{Net Present Value (NPV)}

Berdasarkan hasil analisis proyek pada tingkat bunga bank yang berlaku saat penelitian DF 10\% selama 10 tahun diperoleh NPV sebesar Rp. 1.501.218.718 (NPV > 0), maka usahatani jambu madu deli hijau layak untuk diusahakan atau jumlah rupiah yang dikeluarkan mampu memberikan keuntungan setelah dikurangi dengan beban biaya produksi yang dikeluarkan. 


\section{Net Benefit Cost Ratio (Net B/C)}

Net B/C menunjukkan kemampuan menghasilkan laba persatuan nilai investasi. Hasil perhitungan untuk usahatani jambu madu deli hijau di daerah npenelitian pada tinngkat DF $10 \%$ adalah artinya setiap penambahan biaya sebesar Rp. 1 , maka akan mendapatkan keuntungan sebesar Rp. 9,5 berarti usahatani jambu madu deli hijau di daerah penelitian layak untuk dikembangkan karena Net B/C > 1 .

\section{Internal Rate Of Return (IRR)}

IRR adalah untuk mengetahui presentase keuntungan dari suatu usaha. Dari analisis proyek yang dilakukan selama 10 tahun diperoleh IRR sebesar 87,58\% ini berarti usahatani tersebut layak untuk diusahakan karena nilai IRR lebih besar dari tingkat bunga yang berlaku (IRR > 10\%).

\section{Break Event Point (BEP)}

BEP merupakan titik pulang pokok dimana total revenue sama dengan total cost $(\mathrm{TR}=\mathrm{TC})$, hal ini berarti seluruh biaya pada usahatani ini dapat dikembangkan pada tahun ke-3 bulan ke-5 hari ke-15.

\section{Analisis Sensitivitas}

Analisis sensitivitas bertujuan untuk melihat kemungkinan-kemungkinan yang terjadi dengan hasil analisis suatau usahatani apabila terjadi suatu kesalahan atau perubahan dalam dasar-dasar perhitungan biaya dan manfaat. Dalam analisis ini setiap kemungkinan harus diuji, karena analisis usahatani di dasarkan pada proyeksi-proyeksi yang mengandung banyak ketidakpastian apa yang akan terjadi dimasa akan datang. Adapun asumsi yang dianalisis dalam penelitian ini adalah cost naik $10 \%$ dan benefit tetap.

1. Biaya produksi (cost) naik sebesar $10 \%$ sedangkan penerimaan tetap (benefit) tetap. Kenaikan harga ini diasumsikan sebagai akibat kelangkaan barangbarang produksi sehingga harga barang-barang tersebut meningkat.

2. Penerimaan (benefit) turun $10 \%$ sedangkan biaya produksi (cost) tetap. Penurunan penerimaan ini diasumsikan karena banyaknya jambu madu deli hijau dari luar daerah/kota sehingga harga jual jambu madu dipasaran turun.

Dari kemungkinan-kemungkinan tersebut maka diperoleh hasil analisis sebagai berikut:

1. Kemungkinan I, analisis cost naik $10 \%$ dan benefit tetap, untuk lebih jelas dapat dilihat pada lampiran 7 dan 8.
a. Net Present Value (NPV)$$
=\text { Rp. } 1.465 .484 .443
$$
b. Net Benefit Cost Ratio $($ Net B/C) $=7,61$
c. Internal Rate of Return $($ IRR $)=81,35 \%$
d. Break Event Point (BEP) = 3 tahun, 9 bulan, 0 hari.

2. Kemungkinan II, analisis sensitivitas benefit turun $10 \%$ dan cost tetap, untuk lebih jelas dapat dilihat pada lampiran 9 dan 10.
a. Net Present Value (NPV)
$=$ Rp. 1.315.362.571
b. Net Benefit Cost Ratio $($ Met B/C) $=8,51$
c. Internal Rate of Return (IRR) $\quad=80,6 \%$
d. Break Event Point (BEP)
$=3$ tahun, 7 bulan, 12 hari. 
Dari hasil analisis sensitivitas dapat dilihat bahwa nila NVP $>0$ yaitu untuk cost naik 10\% sebesar Rp.1.465.484.443 dan benefit turun sebesar Rp. 1.315.362.571. Net B/C > 1 yaitu untuk cost naik $10 \%$ sebesar 7,61 dan benefit turun $10 \%$ sebesar 8,51 . IRR > suku bunga yang berlaku $10 \%$ yaitu untuk cost naik $10 \%$ sebesar $81,35 \%$ dan untuk benefit turun $10 \%$ sebesar $80,6 \%$. BEP umur ekonomis usaha budidaya jambu madu deli hijau pada saat cost naik $10 \%$ terjadi pada umur 3 tahun, 9 bulan, 0 hari, dan pada saat benefit turun 10\% terjadi pada umur 3 tahun, 7 bulan, 12 hari. Dengan demikian dapat ditarik kesimpulan bahwa hipotesis dapat diterima. Dalam artian bahwa usaha budidaya jambu madu deli hijau di Kelurahan Sumber Karya Kecamatan Binjai Timur Kota Binjai memliki prospek pengembangan yang layak untuk diusahakan bila ditinjau dari aspek teknis dan finansial.

\section{Aspek Pemasaran Jambu Madu Deli Hijau}

Saluran pemasaran adalah perpindahan barang dari produsen ke konsumen akhir. Proses pemasaran pada usahatani jambu madu deli hijau di Kelurahan Sumber Karya Kecamatan Binjai Timur Kota Binjai melalui beberapa saluran seperti petani ke konsumen, agen mendatangi lokasi usahatani, dan petani juga memasarkan jambu madu deli hijau ke luar kota seperti ke Aceh dan Medan. Aspek pasar yang akan dikaji dalam penelitian ini yaitu dari permintaan dan harga jambu madu deli hijau pada saat penelitian.

\section{Permintaan jambu madu deli hijau}

Berdasarkan hasil penelitian yang telah dilakukan, permintaan jambu madu deli hijau terus meningkat setiap tahunnya, seperti usahatani jambu madu deli hijau di daerah penelitian setiap tahunnya banyak konsumen yang terus berdatangan untuk membeli jambu madu dlei hijau ke lokasi penelitian yang berasal dari berbagai daerah dan kota.

\section{Harga jambu madu deli hijau}

Pada daerah penelitian, petani menjual jambu madu deli hijau kepada konsumen sebesar Rp. 25.000/Kg dan untuk melihat lebih jelas data harga jambu madu deli hijau di Kelurahan Sumber Karya Kecamatan Binjai Timur Kota Binjai adalah yaitu sebagai beikut.

Tabel 4. Data Harga Jual Jambu Madu Deli Hijau Kilogram Per Tahun

\begin{tabular}{|c|c|}
\hline Tahun & $\begin{array}{c}\text { Harga Jual } \\
(\mathrm{Rp} / \mathrm{Kg})\end{array}$ \\
\hline 2010 & 25.000 \\
\hline 2011 & 25.000 \\
\hline 2012 & 35.000 \\
\hline 2013 & 35.000 \\
\hline 2014 & 35.000 \\
\hline 2015 & 37.436 \\
\hline 2016 & 40.042 \\
\hline 2017 & 42.830 \\
\hline 2018 & 45.811 \\
\hline 2019 & 49.000 \\
\hline
\end{tabular}

Sumber: Data Primer (diolah), 2016 menggunakan rumus pertumbuhan 


$$
\left(r=\left\{\left(P_{t} / P_{o}\right)^{(1 / t)}-1\right\} \times 100\right)
$$

Dari Tabel 4 diatas dapat dilihat bahwa terjadi pertumbuhan harga jambu madu deli hija di pasaran sebesar $0,069 \%$ pertahun yang kemungkinan akan terus mengalami pertumbuhan harga di pasar.

\section{KESIMPULAN DAN SARAN}

Dari hasil penelitian, usahatani jambu madu deli hijau memiliki prospek yang baik untuk dikembangkan jika ditinjau dari aspek teknis, aspek finansial dan aspek pasar hal ini dapat disimpulkan sebagai berikut :Dilihat dari aspek teknis, budidaya jambu madu deli hijau di Kelurahan Sumber Karya Kecamatan Binjai Timur Kota Binjai layak untuk diusahakan karena cara membudidayakan jambu madu deli hijau yang sangat mudah dan sederhana, dibudidayakan dengan sistem tabulampot dan masa berbuahnya lebih cepat dari tanaman jambu pada umumnya.

Aspek Finanasial, Kelayakan aspek finansial didasarkan pada nilai kriteria yaitu dari hasil perhitungan pada saat biaya tetap dan cost naik $10 \%$ nilai NPV, IRR, Net B/C dan BEP memenuhi kriteria investasi sehingga usahatani budiddaya jambu madu deli hijau layak untuk diusahakan, dan dari hasil analisis sensitivitas dimana Benefit turun 10\%, nilai NPV, IRR, Net B/C, dan BEP yang dihasilkan memenuhi ketentuan dari uji kelayakan, maka dari itu usahatani budidaya jambu madu deli hijau di Kelurahan Sumber Karya Kecamatan Binjai Timur layak untuk diusahakan. Jika ditinjau dari aspek pasar, jambu madu deli hijau layak untuk diusahakan karena harga jambu madu deli hijau di pasar juga terus meningkat setiap tahunnya mulai dari harga Rp. 25.000 - Rp. 49.000 dan permintaan jambu madu deli hijau terus meningkat setiap tahunnya.

\section{DAFTAR PUSTAKA}

Alwiyah.2011. Analisis Kelayakan Usaha Budidaya Belimbing Dewa Pada Kondisi Risiko Di Kota Depok.Institut Pertanian Bogor.

Assauri. 2006. Manajemen Produksi. Edisiketiga, Lembaga Penerbit Fakultas Ekonomi Universitas Indonesia, Jakarta.

Badan Pusat Statistik. 2014. Sumatera Utara.

Cholic, A. 1993. Evaluasi Proyek (suatu pengantar). Pionir Jaya. Bandung.

Daniel, Moehar. 2004. Pengantar Ekonomi Pertanian. Bumi Aksara. Jakarta.

Pracoyo, Antyo, dan Pracoyo, Kunawangsih, Tri, 2006. Aspek Dasar Ejonomi Mikro, Jakarta: PT Gramedia Widiasarana Indonesia.

Prihatni, R., S.Zulaihati, dan D. Noviarini. 2012. The Comperhension and Aplication of Accounting Information System For The Small and Medium Enterprise. Journal of Global Enterpreneurship, 3 (1). 
Riana. 2013. Prospek Jitu Buidaya Jambu Madu. Jakarta. Trubus.

Sinuraya, S. 1992. Akuntansi Perusahaan Industri. Bintang Kejora, Bogor.

Soekartwai.1993. Agribisnis Teori dan Aplikasi.Bina Aksara.Jakarta.

Suharyadi dan S.K Purwanto, 2003.Statistik Untuk Ekonomi dan Keuangan Modern.Salemba empat, Jakarta. 